\title{
Exigência Nutricional de Cálcio e sua Biodisponibilidade em Alguns Alimentos para Frangos de Corte, no Período de 1 a 21 Dias de Idade ${ }^{1}$
}

\author{
Luciano Moraes Sá2, Paulo Cezar Gomes ${ }^{3}$, Luiz Fernando Teixeira Albino ${ }^{3}$, Horacio Santiago \\ Rostagno ${ }^{3}$, Priscila D'Agostini ${ }^{2}$
}

\begin{abstract}
RESUMO - Foram utilizados 720 pintos de corte de um dia de idade, da linhagem Avian Farm, 360 machos e 360 fêmeas, com o objetivo de determinar a exigência nutricional de cálcio e a disponibilidade relativa do cálcio no fosfato bicálcico, calcário calcítico e calcário dolomítico, utilizando-se o carbonato de cálcio como padrão, sendo atribuído o valor de $100 \%$ de disponibilidade de cálcio. O experimento teve duração de 21 dias. O delineamento experimental adotado foi o inteiramente casualizado, com 12 tratamentos, seis repetições, sendo a unidade experimental representada pelo box contendo cinco machos e cinco fêmeas. Os tratamentos foram constituídos da suplementação da dieta basal com 0,$0 ; 0,25 ; 0,50 ; 0,75 ; 1,00 ;$ e 1,25\% de cálcio proveniente do carbonato de cálcio e dois níveis de cálcio, 0,50 e $0,75 \%$, provenientes de cada uma das fontes de cálcio em teste: fosfato bicálcico e calcários calcítico e dolomítico. Os seis primeiros tratamentos foram utilizados para determinar a exigência de cálcio das aves. Na determinação da disponibilidade de cálcio nas fontes estudadas, os tratamentos com 0,$25 ; 1,00$; e 1,25\% de cálcio, suplementados a partir do carbonato de cálcio, não foram considerados, sendo utilizados apenas os níveis com 0,50 e $0,75 \%$ oriundos desta fonte, além dos níveis provenientes das fontes em teste. Considerando-se as respostas biológicas das aves frente aos níveis de cálcio estudados, determinou-se o valor de 1,02\% para atender a exigência de cálcio para frangos de corte de 1 a 21 dias de idade. Contudo, levando-se em consideração a resistência a quebra óssea, a exigência de cálcio para frangos de corte de 1 a 21 dias seria de 1,20\%. Os valores médios da disponibilidade relativa de cálcio obtidos, considerando-se todas as variáveis estudadas, foram de $99,99 \%$ para o fosfato bicálcico, 84,67\% para o calcário calcítico e de 75,28\% para o calcário dolomítico.
\end{abstract}

Palavras-chave: requerimento de cálcio, disponibilidade, fontes, frangos de corte

\section{Calcium Requirement and Bioavailability of Some Feedstuffs for Broiler Chicks from 1 to 21 Days Old}

ABSTRACT - One experiment was carried to determine the nutritional requirement of calcium for broilers in the starting phase (1 to 21 days) and to evaluate the availability of this mineral in dicalcium phosphate, calcitic limestone and dolomitic limestone. Seven hundred and twenty 1-day old Avian Farm broiler chicks (360 from each sex) were used. The experiment lasted 21 days. A completely randomized design, with 12 treatments, six replications and 10 birds per experimental box (five males and five females) was used. A basal diet was formulated to meet the birds nutritional requirements, except for the calcium, that remained deficient at the level of $0.161 \%$. The basal diets were supplemented with $0.01,0.25,0.50,0.75,1.00$ and $1.25 \%$ calcium levels from calcium carbonate and two levels of calcium $(0.50$ and $0.75 \%)$ from each source in test: dicalcium phosphate, calcitic limestone and dolomitic limestone. The first six treatments were used to estimate the calcium requirements of broilers. To determine the calcium availability in the studied sources, the treatments with $0.25,1.00$ and $1.25 \%$ of calcium were not considered. At the end of experiment, 144 birds were sacrificed by cervical dislocation for the purpose of determining the tibia breaking strength, calcium and ash levels in their tibias. According to the biological values observed for the chickens, the estimated calcium requirements were of $1.02 \%$ for broilers from 1 to 21 days old. However, according to the tibia breaking strength, the calcium requirement suggested for broilers from 1 to 21 days of age would be $1.20 \%$. The average values of relative calcium availability were $99.99 \%$ for dicalcium phosphate, $84.67 \%$ for calcitic limestone and $75.28 \%$ for dolomitic limestone.

Key Words: calcium requirement, availability, sources, broiler chicks

\section{Introdução}

Os minerais compreendem cerca de $4 \%$ da composição corporal dos animais vertebrados; o cálcio e o fósforo respondem por mais da metade desta quantia. O cálcio é o mineral mais abundante no corpo animal, estando presente, aproximadamente, $99 \%$ no esqueleto ósseo e dentes, e o restante espalhado por fluidos e tecidos do corpo (Underwood, 1981). O cálcio é requerido pelas aves para formação e manutenção da estrutura óssea, adequado crescimento e utilização eficiente dos alimentos, formação da casca do ovo,

\footnotetext{
${ }^{1}$ Parte da tese de Mestrado do primeiro autor apresenta da à Universidade Federal de Viçosa.

2 Estudante de Doutorado/UFV. E.mail: lucianomsa@uol.com.br; priscila@vicosa.ufv.br

3 Professor do DZO/UFV. E.mail: pcgomes@ufv.br
} 
transmissão de impulsos nervosos, coagulação sangüínea, contração muscular, ativador de sistemas enzimáticos e envolvimento com a secreção de diferentes hormônios.

Waldroup (1996) relata que o sintoma primário da deficiência de cálcio em animais jovens é o raquitismo, que é caracterizado pela calcificação anormal dos ossos. O cálcio e o fósforo não são depositados em quantidade suficiente na matriz óssea para desenvolver ossos densos e fortes. O raquitismo em estádio avançado pode ser detectado por intermédio da observação de juntas entumecidas e inchadas, alargamento das terminações ósseas e má formação de bicos, que apresentam um aspecto emborrachado. A osteomalacia é indicativo da deficiência de cálcio ou fósforo em animais velhos.

Cálcio e fósforo são elementos intimamente associados ao metabolismo, ocorrendo no organismo combinados entre si na maioria das vezes, de modo que a carência de um ou de outro na dieta limita o valor nutritivo de ambos (Maynard et al., 1984). Muitos fatores influenciam a utilização e o metabolismo do cálcio no organismo, como por exemplo: a correta relação de cálcio e fósforo na dieta, a presença da vitamina $\mathrm{D}$, a disponibilidade biológica dos suplementos utilizados nas rações e a idade dos animais.

Os grãos e as sementes são a base da alimentação das aves e possuem teores de cálcio muito baixos, em quantidade insuficiente para suprir os requisitos nutricionais. Segundo Gueguem (1990), o cálcio de origem vegetal é pouco solúvel e absorvível, por estar em grande parte insolubilizado sob a forma de fitato ou oxalato. Assim, é incontestável a importância da suplementação de cálcio para corrigir esta deficiência.

Nas rações para aves, o cálcio é usualmente suplementado na forma de carbonato de cálcio proveniente do calcário, mas outras fontes podem ser utilizadas, como a farinha de ostras e uma série de produtos quimicamente processados. De acordo com Reid \& Weber (1976), as fontes de cálcio diferem em sua origem (deposição animal ou mineral) e no tamanho de sua partícula, resultando em características físico-químicas diferentes.

Geralmente, considera-se que o cálcio proveniente das diversas fontes de suplementação seja igualmente disponível, entretanto, pouco se conhece sobre a disponibilidade desse mineral nos ingredientes e/ou nas fontes naturais de cálcio (Fialho et al., 1992).
Assim, segundo Veloso et al. (1995), é possível que os requisitos nutricionais das aves não sejam completamente atendidos, causando deficiências no crescimento e na mineralização óssea.

A disponibilidade biológica refere-se àquela porção do nutriente que é efetivamente utilizada pelo animal, sendo expressa em porcentagem do contido no alimento. A grande variação da disponibilidade do cálcio nos alimentos deve-se principalmente à composição química da fonte suplementar utilizada, à combinação química e/ou da associação física do cálcio com outros componentes, formando em alguns casos quelatos e fitatos de baixa solubilidade ou baixa disponibilidade (Nunes, 1995).

Com relação à exigência de cálcio para frangos de corte, Edwards Jr. et al. (1960) sugeriram o nível de cálcio entre 0,9 e 1,5\%. Entretanto, Yoshida \& Hoshii (1982) recomendaram 1,30\% de cálcio e $0,75 \%$ de fósforo para frangos de corte na fase de 1 a 21 dias de idade. De acordo com Hurwitz et al. (1995), a exigência de cálcio para máximo crescimento é de $1,01 \%$, enquanto $1,33 \%$ é o nível necessário para maior deposição de cinzas nos ossos, para frangos de corte na fase inicial.

Rojas et al. (1980) observaram que a disponibilidade de cálcio do fosfato de rocha foi de $65,5 \%$ para frangos de corte. Osorio \& Jensen (1986) também confirmaram estes resultados, pois asseguraram que a biodisponibilidade de cálcio no fosfato de rocha está entre 65,0 e $68,0 \%$. Veloso et al. (1994) determinaram os valores de biodisponibilidade de cálcio em cinco fosfatos semi-elaborados para frangos de corte, utilizando a variável cinza óssea. Os valores de biodisponibilidade do cálcio dos fosfatos foram 101,5; 93,$0 ; 101,3 ; 92,5$; e $85,8 \%$, respectivamente, para fosfato de Araxá (20,1\% de $\mathrm{P}_{2} \mathrm{O}_{5}$ ); fosfato de Araxá $\left(24,00 \%\right.$ de $\left.\mathrm{P}_{2} \mathrm{O}_{5}\right)$; fosfato de Araxá $\left(26,9 \%\right.$ de $\left.\mathrm{P}_{2} \mathrm{O}_{5}\right)$; fosfato de Araxá $\left(28,0 \%\right.$ de $\left.\mathrm{P}_{2} \mathrm{O}_{5}\right)$; e termofosfato.

O presente trabalho foi conduzido com o objetivo de determinar a exigência de cálcio para frangos de corte na fase de 1 - 21 dias de idade, bem como a biodisponibilidade deste mineral no fosfato bicálcico e nos calcários calcítico e dolomítico.

\section{Material e Métodos}

O presente trabalho foi realizado no Setor de Avicultura do Departamento de Zootecnia da Universidade Federal de Viçosa (UFV), no período de 24 de agosto a 13 de setembro de 2000. 
Foram utilizados 720 pintos de corte de um dia de idade, da linhagem Avian Farm, 360 machos e 360 fêmeas, vacinados contra Bouba Aviária e doença de Marek no incubatório. As aves foram criadas de acordo com as recomendações de manejo descritas por Gomes et al. (1996). O experimento teve duração de 21 dias. O delineamento experimental adotado foi o inteiramente casualizado, com 12 tratamentos, seis repetições, sendo a unidade experimental representada pelo box, contendo cinco machos e cinco fêmeas.

As aves foram alojadas em um galpão de alvenaria, com dimensões de 29,20 x 12,60 m, com 2,80 m de pé-direito, cobertos com telha de cimento amianto, com lanternim, laterais possuindo muretas de $0,65 \mathrm{~m}$ de altura e o restante fechado com tela de meia polegada e cortinas plásticas com abertura de baixo para cima. As aves ficaram em boxes de 2,10 x 1,00 $\mathrm{m}$, com piso de cimento, cobertos com cepilho de madeira.

O programa de luz adotado foi o contínuo, com 24 horas de luz (natural + artificial), durante todo o período experimental, utilizando-se lâmpadas de $60 \mathrm{~W}$. A temperatura no interior do galpão foi aferida diariamente por intermédio de termômetros de máxima e mínima, localizados à altura do dorso dos animais, durante todo o ensaio.

A composição química dos ingredientes utilizados na formulação das dietas encontra-se na Tabela 1.

Segundo as recomendações de Rostagno et al. (2000), foi confeccionada uma dieta basal constituída de milho e farelo de soja, suplementada com vitaminas e minerais (Tabela 2), atendendo as exigências nutricionais das aves, com exceção do cálcio, que permaneceu deficiente no nível de 0,161\%.

Os tratamentos foram constituídos da suplementação da dieta basal com 0,$0 ; 0,25 ; 0,50$; 0,$75 ; 1,00 ;$ e $1,25 \%$ de cálcio proveniente do carbonato de cálcio e dois níveis de cálcio 0,50 e $0,75 \%$, provenientes de cada uma das fontes de cálcio: fosfato bicálcico e calcários calcítico e dolomítico. Os seis primeiros tratamentos foram utilizados para determinar a exigência de cálcio das aves. Na determinação da disponibilidade de cálcio, os tratamentos com 0,$25 ; 1,00$; e $1,25 \%$ de cálcio, suplementados a partir do carbonato de cálcio, não foram considerados, sendo utilizados apenas os níveis com 0,50 e $0,75 \%$ oriundos desta fonte, além dos níveis provenientes das fontes em teste.

As aves receberam ração e água à vontade. As pesagens foram realizadas no início e final do experimento para averiguação de ganho de peso, consumo de ração e conversão alimentar. Com o término do experimento, foram abatidas 144 aves com peso médio do box (duas aves por box), para extração das tíbias, visando à medição da resistência à quebra e análises de cinzas e cálcio.

As tíbias direitas foram destinadas para o teste de resistência à quebra, e as esquerdas, após a retirada de gordura no extrator "Soxhlet", foram colocadas na mufla a $600^{\circ} \mathrm{C}$, durante quatro horas, para determina-

Tabela 1 - Teores de matéria seca, proteína bruta, cálcio, fósforo e magnésio dos ingredientes utilizados nas dietas experimentais ${ }^{1}$

Table 1 - Dry matter, crude protein, calcium, phosphorus and magnesium contents of the ingredients used in the experimental diets

\begin{tabular}{|c|c|c|c|c|c|}
\hline $\begin{array}{l}\text { Alimento } \\
\text { Feedstuff }\end{array}$ & $\begin{array}{c}\text { Matéria seca } \% \\
\text { Dry matter }\end{array}$ & $\begin{array}{l}\text { Proteína bruta \% } \\
\text { Crude protein }\end{array}$ & $\begin{array}{l}\text { Cálcio \% } \\
\text { Calcium }\end{array}$ & $\begin{array}{l}\text { Fósforo \% } \\
\text { Phosphorus }\end{array}$ & $\begin{array}{l}\text { Magnésio \% } \\
\text { Magnesium }\end{array}$ \\
\hline $\begin{array}{l}\text { Milho } \\
\text { Corn }\end{array}$ & 87,11 & 7,80 & 0,03 & 0,248 & - \\
\hline $\begin{array}{l}\text { Farelo de soja } \\
\text { Soybean meal }\end{array}$ & 87,74 & 44,00 & 0,267 & 0,586 & - \\
\hline $\begin{array}{l}\text { Fosfato bicálcico } \\
\text { Dicalcium phosphate }\end{array}$ & - & - & 21,85 & 18,56 & - \\
\hline $\begin{array}{l}\text { Fosfato monoamônio } \\
\text { Monoammonium phosphate }\end{array}$ & - & - & 0,46 & 23,82 & - \\
\hline $\begin{array}{l}\text { Carbonato de cálcio } \\
\text { Calcium carbonate }\end{array}$ & - & - & 39,65 & - & 1,03 \\
\hline $\begin{array}{l}\text { Calcário calcítico } \\
\text { Calcitic limestone }\end{array}$ & - & - & 34,85 & - & 2,78 \\
\hline $\begin{array}{l}\text { Calcário dolomítico } \\
\text { Dolomitic limestone }\end{array}$ & - & - & 21,15 & - & 10,49 \\
\hline
\end{tabular}

${ }^{1}$ Análises realizadas no Laboratório de Nutrição Animal do Departamento de Zootecnia da UFV.

${ }^{1}$ Analyses performed at the Animal Nutrition Lab of the Animal Science Department/UFV. 
Tabela 2 - Composição percentual da dieta basal

Table 2 - Composition of the basal diet (\%)

Ingredientes

Ingredients

Milho (Corn)

Farelo de soja (Soybean meal)

50,39

Óleo vegetal (Vegetal oil)

38,50

Fosfato monoamônio (Monoammonium phosphate) $\quad 1,35$

Calcário (Limestone)

0,10

Sal (Salt)

0,40

Bacitracina de zinco (Zinc bacitracin)

0,02

$\begin{array}{ll}\text { Cloreto de colina (60\%) (Choline chloride) } & 0,10\end{array}$

Anticoccidiano (Anticoccidial agent $)^{1} \quad 0,10$

$\begin{array}{ll}\text { DL-metionina(99\%) (DL-methionine) } & 0,23\end{array}$

BHT

Mistura mineral (Mineral mix) ${ }^{2} \quad 0,05$

$\begin{array}{lr}\text { Mistura vitamínica (Vitamin mix) } & 0,10\end{array}$

Caulin (inert) $\quad 5,35$

$\begin{array}{ll}\text { Total } & 100\end{array}$

Composição calculada

Calculated composition

\begin{tabular}{lr}
\hline Proteína bruta (\%) (Crude protein) & 21,05 \\
Energia metabolizável (Mcal/kg) (Metabolizable energy) & 3,050 \\
Cálcio (\%) (Calcium) & 0,161 \\
Fósforo disponível (\%) (Available phosphorus) & 0,451 \\
Metionina (\%) (Methionine) & 0,564 \\
Lisina (\%) (Lysine) & 1,196 \\
Metionina + cistina (\%) (Methionine + cystine) & 0,903 \\
Treonina (\%) (Threonine) & 0,825 \\
Triptofano (\%) (Thryptophan) & 0,285 \\
Sódio (\%) (Sodium) & 0,201
\end{tabular}

\footnotetext{
${ }^{1}$ Anticoccidiano - (20\% de monensina sódica).

${ }^{2}$ Níveis de garantia/kg do produto (Guarantee levels/kg of product): Fe, 100,0 g; Co 2,0 g; Cu 20,0 g; Mn 106,0 g; I 2,0 g; e veículo gsp 1000 g.

${ }^{3}$ Níveis de garantia/kg do produto (Guarantee levels/kg of product): vit. A, $10.000 .000 \mathrm{UI}$; vit. D3, $2.000 .000 \mathrm{UI}$; vit. E, $30.000 \mathrm{UI}$; vit. B, 2,0 g;

vit. B6, 3,0 g; ác. pantotênico (panthotenic acid), 12,0 g; biotina (biotin), 0,1 g; vit. K3, 3,0 g; ác. fólico, 1,0 g; ác. nicotínico (nicotinic acid), 50,0 g; bacitracina de Zn (zinc bacitracin), 10,0 g; BHT, 5,0 g; vit. B12, $15000 \mathrm{mcg}$; Se, 0,25 g e veículo gsp $1000 \mathrm{~g}$.
}

ção das cinzas. O teor de cálcio nos ossos foi obtido de acordo com a metodologia proposta por Silva (1998). As análises de resistência à quebra óssea foram realizadas utilizando-se os ossos in natura, em uma prensa computadorizada que registra a resistência de materiais (Instron Corporation Series IX Automated Materials Testing System 1,09). Os ossos foram colocados na posição horizontal sobre dois suportes, sendo a pressão aplicada no centro dos mesmos. A quantidade máxima de força aplicada ao osso antes de sua ruptura foi considerada como resistência à quebra.

Os valores da exigência de cálcio foram estimados por intermédio das variáveis de ganho de peso, conversão alimentar, teores de cálcio e cinzas nos ossos (em porcentagem e em gramas) e resistência à quebra dos ossos, utilizando-se os modelos de regressão quadrática, conforme ajuste dos dados obtidos para cada variável, interpretando-se as respostas biológicas das aves. A escolha entre os modelos foi feita pela observação dos coeficientes de regressão e pela soma de quadrados dos desvios, em que foram privilegiados os maiores coeficientes e as menores somas de quadrado. De acordo com Euclydes \& Rostagno (2001), as exigências determinadas pelo modelo quadrático geralmente são superestimadas; assim, optou-se pela utilização de $95 \%$ do máximo valor encontrado para cada exigência, conforme Kidd et al. (1999). As variáveis acima citadas foram consideradas dependentes e os níveis de cálcio em estudo, como variáveis independentes na análise de regressão.

Os dados de desempenho e ossos foram utilizados como critério para a determinação da biodisponibilidade do cálcio. Os mesmos foram considerados variáveis dependentes (y) e o consumo de cálcio na dieta basal, como variável independente $(\mathrm{x})$, na determinação da equação de regressão linear múltipla, utilizando-se o seguinte modelo estatístico: 
$\mathrm{Yi}=\mathrm{B}_{0}+\mathrm{B}_{1} \mathrm{x}_{1}+\mathrm{B}_{2} \mathrm{x}_{2}+\mathrm{B}_{3} \mathrm{x} 3+\mathrm{B}_{4} \mathrm{x}_{4}+\mathrm{B}_{5} \mathrm{x}_{5}+\mathrm{e}_{\mathrm{i}}$ em que: $x_{1}=$ consumo de cálcio na ração basal; $\mathrm{x}_{2}=$ consumo de cálcio na ração com carbonato de cálcio; $\mathrm{x}_{3}=$ consumo de cálcio na ração com fosfato bicálcico; $\mathrm{x}_{4}=$ consumo de cálcio na ração com calcário calcítico; $\mathrm{x}_{5}=$ consumo de cálcio na ração com calcário dolomítico; $\mathrm{e}_{\mathrm{i}}=$ erro aleatório associado a cada observação.

O cálcio proveniente do carbonato de cálcio foi considerado como $100 \%$ disponível e determinaramse os valores de disponibilidade relativa ao cálcio no fosfato bicálcico e nos calcários calcítico e dolomítico, pela relação dos coeficientes de regressão utilizandose a técnica do "Slope Ratio Technique".

De acordo com Fialho et al. (1992), a metodologia usada neste experimento não permite a determinação da disponibilidade verdadeira do cálcio, já que nem todo o cálcio ingerido é absorvido metabolicamente pelo animal. Entretanto, essa metodologia permite comparar a relativa disponibilidade de várias fontes de suplementação de cálcio, utilizando-se como referência uma fonte altamente disponível como o carbonato de cálcio.

As análises estatísticas dos parâmetros avaliados neste experimento foram realizadas por intermédio programa SAEG (Sistema para Análise Estatística e Genética), versão 7.0 desenvolvido pela Universidade Federal de Viçosa - UFV (1997).

\section{Resultados e Discussão}

Na Tabela 3, encontra-se o resumo da temperatura aferida no interior do galpão durante o período experimental.

Tabela 3 - Resumo da temperatura no interior do galpão durante o experimento

Table 3 - Temperature in the poultry-sheds during the experiment

\begin{tabular}{lc}
\hline $\begin{array}{l}\text { Temperatura } \\
\text { Temperature }\end{array}$ & ${ }^{\circ} \mathrm{C}$ \\
\hline $\begin{array}{l}\text { Máxima média } \\
\text { Average maximum }\end{array}$ & 29,33 \\
$\begin{array}{l}\text { Mínima média } \\
\text { Average minimum }\end{array}$ & 21,46 \\
$\begin{array}{l}\text { Máxima absoluta } \\
\text { Absolute maximum }\end{array}$ & 36,00 \\
$\begin{array}{l}\text { Mínima absoluta } \\
\text { Absolute minimum }\end{array}$ & 18,00 \\
\hline
\end{tabular}

R. Bras. Zootec., v.33, n.1, p.157-168, 2004
Exigência nutricional de cálcio para frangos de corte de 1 a 21 dias de idade

As variáveis de desempenho dos frangos de corte de 1 a 21 dias de idade estão apresentadas na Tabela 4.

O ganho de peso (GP) foi influenciado pelos níveis de cálcio estudados, sendo que as maiores taxas de ganho foram obtidas a partir do nível de $0,66 \%$ de cálcio. Contudo, a taxa de ganho de peso observada no nível de $0,91 \%$ de cálcio na dieta apresentou maior valor, enquanto os menores valores foram encontrados nos níveis de 0,16 e $0,44 \%$ de cálcio dietético.

A conversão alimentar (CA) foi influenciada pelos níveis de cálcio, sendo a pior taxa obtida com o nível de $0,16 \%$, seguida pelo nível de $0,41 \%$ de cálcio. Houve pouca variação nos valores de CA, quando o nível de cálcio variou de 0,66 a $1,41 \%$ na dieta, sendo, nesses intervalos, obtidos os melhores valores.

As exigências de cálcio estimadas pelo modelo de regressão quadrático foram de 0,97 e $1,01 \%$, para as variáveis de GP e CA, respectivamente (Tabela 5). Estes valores foram superiores àqueles encontrados por Cabral (1999), que obteve níveis de 0,89 e 0,93\% de cálcio na ração para melhores taxas de GP e CA, para frangos de corte de 1 a 21 dias de idade. Rostagno et al. (2000) recomendam o nível de 0,944\% de cálcio para pintos de corte na fase inicial e o NRC (1994), 1\% de cálcio para as aves nesta mesma fase. Contudo, Edwards Jr. \& Veltmann Jr. (1983) reportaram que a máxima taxa de ganho de peso até os 14 dias de idade foi obtida em rações contendo $1,49 \%$ de cálcio e $1,01 \%$ de fósforo.

De acordo com os dados obtidos, observou-se que não houve redução no GP e CA nos níveis mais altos de cálcio, o que contraria os resultados encontrados por Shafey e McDonald (1991). Esses autores afirmam que animais que consomem elevados teores de cálcio apresentam redução na performance, devido provavelmente à diminuição na utilização de outros nutrientes da dieta. O cálcio em excesso diminuiria a absorção da fração solúvel de outros minerais nutricionalmente importantes, pela formação de complexos insolúveis com o cálcio (Edwards Jr. et al., 1992).

As médias das variáveis ósseas, de frangos de corte de 1 a 21 dias, são apresentadas na Tabela 4.

As variáveis ósseas foram influenciadas pelos níveis de cálcio estudados. Em relação à porcentagem de cálcio nos ossos (CAOP) e ao teor de cinza nos ossos, em porcentagem (COP) e em gramas (COG), observou-se que houve pouca variação nos 


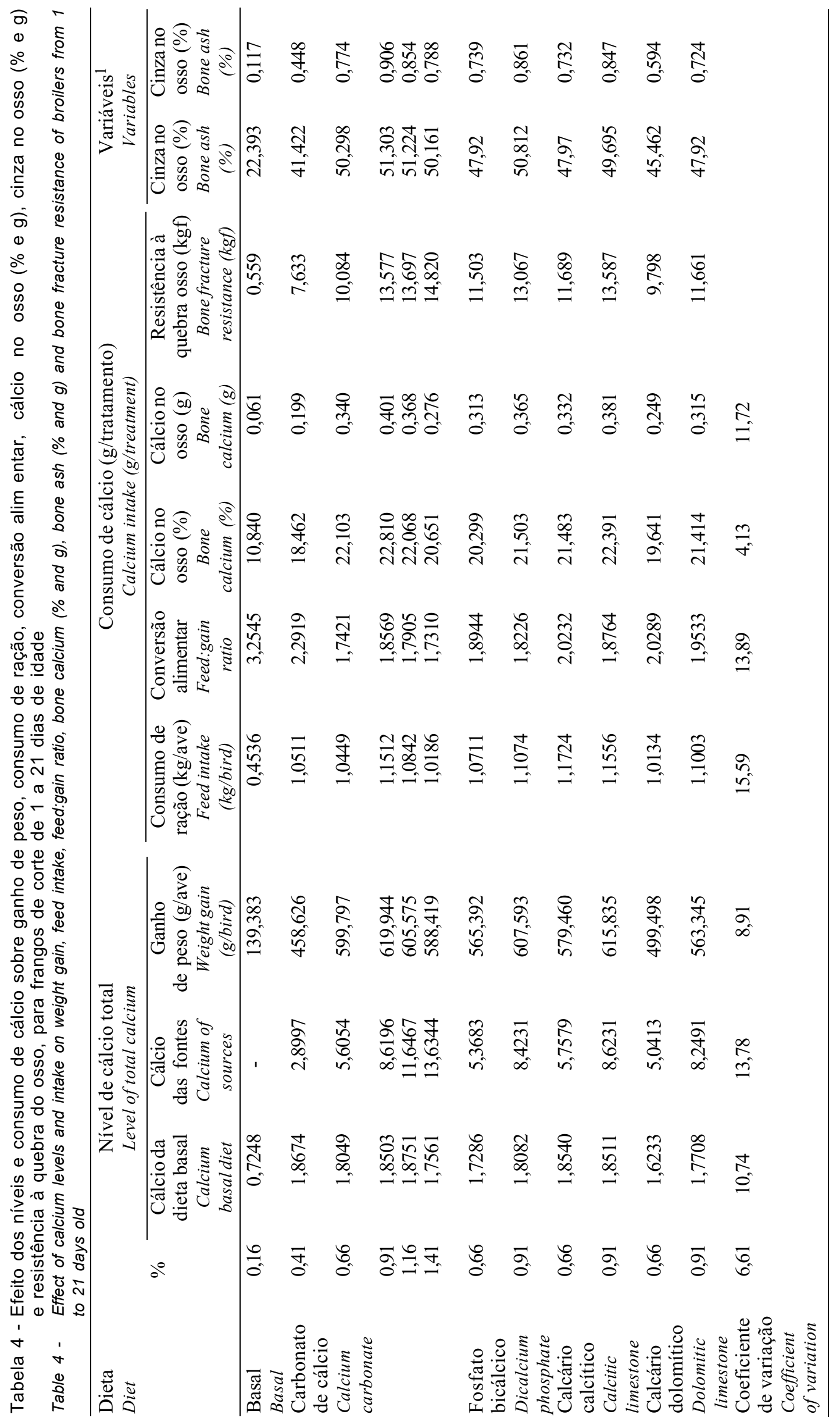


Tabela 5 - Estimativas da exigência de cálcio para frangos de corte na fase inicial (1 a 21 dias de idade), considerando a taxa de ganho de peso e conversão alimentar, ajustadas por modelo de regressão

Table 5 - Estimates of calcium requirement for broiler in the initial phase (from 1 to 21 days old), considering weight gain and feed:gain ratio, adjusted by the regression model

\begin{tabular}{|c|c|c|c|c|c|}
\hline $\begin{array}{l}\text { Modelo } \\
\text { Model }\end{array}$ & $\begin{array}{l}\text { Equação de regressão } \\
\text { Regression equation }\end{array}$ & Pmáx/PMín & $\begin{array}{l}\text { Exigência cálcio }^{1}(\%) \\
\text { Calcium requirement }^{1}\end{array}$ & $\mathrm{R}^{2}$ & SQD \\
\hline
\end{tabular}

Quadrático

Quadratic

Ganho de peso

Weight gain

Conversão alimentar $\hat{\mathrm{Y}}=3,72269-3,92593 \mathrm{x}+1,84260 \mathrm{x} 2$

$$
\hat{Y}=-27,8401+1344,17 x-658,331 x 2 \quad 656,58
$$

Feed:gain ratio

\footnotetext{
1 Representa $95 \%$ do valor máximo encontrado pela equação de regressão, indicando o nível adequado de cálcio total para cada variável ${ }^{1}$ Represents $95 \%$ of the minimum value obtained by the regression equation, indicating the ideal total calcium levels for each levels.

** $(\mathrm{P} \leq 0,01),{ }^{*}(\mathrm{P} \leq 0,05)$.

Pmáx (Ponto de máxima) e Pmín (ponto de mínima).

SQD - Soma de quadrados dos desvios (Sum of deviation squares).
}

valores entre os níveis a partir de 0,66 a 1,41\% de cálcio na dieta, na qual foram encontradas as melhores respostas. Contudo, o nível de $0,91 \%$ de cálcio na dieta apresentou maiores valores entre essas variáveis.

Quanto aos valores de cálcio em gramas no osso (CAOG), novamente pode-se observar que o nível de $0,91 \%$ de cálcio apresentou o maior valor, seguido dos níveis de 1,16 e $0,66 \%$ de cálcio, os quais apresentaram valores superiores aos demais níveis de cálcio.

A variável resistência à quebra óssea (RQO) apresentou comportamento distinto em relação às demais variáveis. À medida que se elevou a porcentagem de cálcio na dieta, aumentaram-se os valores de resistência, sendo o maior valor obtido no nível de $1,41 \%$ de cálcio na dieta.

Estimando-se os valores de exigência de cálcio pelo modelo de regressão quadrática, as exigências de cálcio estimadas para CAOP, CAOG, RQO, COP e COG foram de 0,$93 ; 1,01 ; 1,20 ; 0,98$; e $1,02 \%$, respectivamente (Tabela 6 ).

Segundo Azevedo (1980), frangos de corte necessitam de, no máximo, $1,0 \%$ de cálcio na dieta para incorporarem o máximo de minerais nos ossos. Pesquisando o efeito da influência do cálcio na fragilidade dos ossos de frangos de corte criados em gaiolas, Yates \& Brunson (1971) concluíram que os ossos dos animais que receberam os níveis mais elevados de cálcio na dieta $(0,90 \%)$ apresentaram maior resistência à quebra e menor incidência de deformações. O NRC (1984) recomenda 1,1\% de cálcio para melhor desenvolvimento de frangos de corte de 1 a 21 dias de idade.

Em relação à deposição de cálcio no osso em porcentagem, Cabral (1999) obteve valores de exigência pouco inferiores aos encontrados neste trabalho, sendo a maior deposição observada no nível de $0,87 \%$ para machos e $0,82 \%$ para fêmeas. Edwards Jr. (1988) também observou resultados semelhantes.

Rowland et al. (1971) e Hulan et al. (1985) verificaram que a resistência à quebra da tíbia aumentou com a elevação da relação cálcio e fósforo na dieta para aves, conforme observado neste experimento. Estes últimos autores reportam que a maior resistência à quebra óssea foi obtida no nível de $1,37 \%$ de cálcio, sendo superior ao valor encontrado neste experimento, que foi de $1,20 \%$. Cabral (1999) reporta que frangos de corte machos apresentaram máxima resistência no nível de $0,96 \%$ de cálcio e as fêmeas, no nível de $1,01 \%$ de cálcio. Segundo Crenshaw et al. (1981), na determinação da RQO, deve ser considerada também a área sobre a qual a força é aplicada, e não apenas a medida de força como foi utilizado neste experimento.

Observou-se que o teor de cinzas nos ossos aumentou com a elevação do nível de cálcio nos tratamentos estudados. Resultados semelhantes foram verificados por Waldroup et al. (1974) e Hulan et al. (1985). Contudo, Cabral (1999) verificou que houve diminuição no teor de cinza, à medida que se elevou o nível dietético de cálcio, em que a deposição máxima ocorreu nos níveis 0,85 e $0,86 \%$, para machos e fêmeas, respectivamente. Edwards Jr. et al. (1992) concluíram que, na fase inicial de criação de frangos de corte, o nível de cálcio dietético para satisfazer a exigência de máxima cinza óssea deve ser de $0,82 \%$.

As estimativas de exigência de cálcio para fran- 
Tabela 6 - Estimativas da exigência de cálcio para frangos de corte na fase inicial (1 a 21 dias de idade), considerando o cálcio no osso (\% e g) e a resistência à quebra dos ossos e das cinzas ósseas (\% e g), ajustadas por meio do modelo de regressão

Table 6 - Estimates of calcium requirement for broiler in the initial phase (from 1 to 21 days old), considering bone calcium (\% and $\mathrm{g})$, bone fracture resistance and bone ash (\% and $\mathrm{g})$, adjusted by the regression model

\begin{tabular}{lccc}
\hline $\begin{array}{l}\text { Modelo } \\
\text { Model }\end{array}$ & $\begin{array}{c}\text { Equação de regressão } \\
\text { Regression equation }\end{array}$ & $\begin{array}{c}\text { Pmáx/PMín } \\
\text { Exigência cálcio }{ }^{1}(\%) \\
\text { Calcium requirement }^{1}\end{array}$ & $\mathrm{R}^{2}$ \\
\hline
\end{tabular}

\section{Quadrático}

Quadratic

Cálcio no osso (\%)

Bone calcium (\%)

Cálcio no osso $(\mathrm{g})$

Bone calcium ( $g$ )

Resistência à quebra (kgf)

Bone fracture resistance ( $k g f)$

Cinza no osso (\%)

Bone ash (\%)

Cinza no osso (g)

Bone ash (g)

${ }_{1}^{1}$ Representa $95 \%$ do valor máximo encontrado pela equação de regressão, indicando o nível adequado de cálcio total para cada variável

${ }^{1}$ Represents $95 \%$ of the minimum value obtained by the regression equation, indicating the ideal total calcium levels for each levels.

** $(P \leq 0,01) ;{ }^{*}(P \leq 0,05)$.

Pmáx (Ponto de máxima) e Pmín (ponto de mínima).

SQD - Soma de quadrados dos desvios (Sum of deviation squares).

gos de corte de 1 a 21 dias de idade variaram pelo modelo quadrático de, no mínimo, $0,93 \%$ para a variável CAOP e, no máximo, de $1,20 \%$ para a variável RQO. Com exceção da exigência de cálcio para CAOP, pode-se observar que os requerimentos para suprir as exigências dos parâmetros ósseos foram superiores àqueles para as variáveis de desempenho. Fato semelhante foi observado por Runho et al. (2001) e Brugalli (1996), trabalhando com exigência de fósforo disponível, e por Cabral (1999), trabalhando com exigência de cálcio. Edwards Jr. et al. (1963) concluíram que o requerimento de cálcio para frangos de corte variou de $1,0 \%$ para máximo crescimento a $1,40 \%$ para máxima deposição de cinzas.

Levando-se em consideração as respostas biológicas das aves nos diferentes níveis de cálcio estudados, sugere-se o valor de $1,02 \%$ de cálcio como a exigência para frangos de corte de 1 a 21 dias. Contudo, levando-se em consideração a RQO, que é uma variável importante no abate e processamento de aves, a exigência de cálcio para frangos de corte de 1 a 21 dias seria de $1,20 \%$.

\section{Disponibilidade relativa do cálcio}

Encontram-se na Tabela 7 os valores de disponibilidade relativa de cálcio no fosfato bicálcico e nos calcários calcítico e dolomítico, estimados por intermédio das variáveis GP, CA, CAOP, CAOG, RQO,
COP e COG, bem como as equações de regressão linear múltipla e seus respectivos coeficientes de regressão $\left(\mathrm{R}^{2}\right)$.

A taxa de ganho de peso das aves apresentou valores próximos entre os níveis de 0,66 e $0,91 \%$ de cálcio oriundo do calcário calcítico, fosfato bicálcico e carbonato de cálcio e entre o nível de $0,91 \%$ de cálcio proveniente do calcário dolomítico (Tabela 4). Os valores de disponibilidade relativa de cálcio obtidos com o do GP foram de $99,99 \%$ para o fosfato bicálcico, 82,29\% para o calcário calcítico e $69,92 \%$ para o calcário dolomítico.

A melhor taxa de conversão alimentar foi encontrada no nível de $0,91 \%$ de cálcio, proveniente do fosfato bicálcico, entretanto, houve pouca variação nos valores de CA entre os tratamentos (Tabela 4). Os valores de disponibilidade obtidos com a CA para os calcários calcítico e dolomítico foram próximos, 68,07 e $66,35 \%$, respectivamente, e para o fosfato bicálcico foi superior ao padrão, apresentando o valor de $111,45 \%$.

Houve pouca variação entre os valores de CAOP para os níveis de cálcio $(0,66$ e $0,91 \%)$ e as fontes de cálcio em teste (Tabela 4). Com esta variável, o calcário calcítico apresentou o maior valor de disponibilidade de cálcio $(70,87 \%)$, seguido do calcário dolomítico $(68,73 \%)$ e fosfato bicálcico $(57,20 \%)$.

Os valores de CAOG variaram de 0,249 a 0,381 
para os níveis de 0,66 e $0,91 \%$ de cálcio dietético, proveniente do calcário dolomítico e calcário calcítico, respectivamente (Tabela 4). Os valores de disponibilidade de cálcio encontrados para o fosfato bicálcico e calcário calcítico foram próximos, 87,36 e 87,37\%, respectivamente, e para o calcário dolomítico foi de $59,35 \%$.

Com relação à resistência a quebra óssea, observou-se que o nível de $0,66 \%$ de cálcio na dieta, em todas as fontes em teste, apresentou menor valor de resistência em comparação, com o nível de $0,91 \%$ de cálcio; o nível de $0,66 \%$ de cálcio proveniente do calcário dolomítico apresentou o menor valor e o nível de $0,91 \%$ oriundo do calcário calcítico, o maior valor (Tabela 4). Os valores da disponibilidade relativa de cálcio foram de $116,99 \%$ para o fosfato bicálcico, $107,70 \%$ para o calcário calcítico e $92,91 \%$ para o calcário dolomítico.

Os resultados de COP apresentaram comportamento semelhante ao encontrado para a resistência à quebra do osso (Tabela 4). De acordo com esta variável, os valores da disponibilidade relativa de cálcio foram de $129,69 \%$ para o fosfato bicálcico, $94,83 \%$ para o calcário calcítico e $107,01 \%$ para o calcário dolomítico.

Considerando o teor de COG, constatou-se que os tratamentos com $0,91 \%$ de cálcio, proveniente do fosfato bicálcico e calcário calcítico, apresentaram os maiores valores. Os valores obtidos para essa variável variaram de 0,594 a 0,861 para os níveis de 0,66 e $0,91 \%$ de cálcio dietético provenientes do calcário dolomítico e fosfato bicálcico, respectivamente (Tabela 4). Os valores de disponibilidade relativa de cálcio, obtidos a partir dessa variável, foram de 97,28\% para o fosfato bicálcico, $81,58 \mathrm{e}$ $62,96 \%$ para os calcários calcítico e dolomítico, respectivamente.

Houve grande variação nos valores de disponibilidade relativa de cálcio para as fontes testadas, quando estimados por intermédio de cada uma das variáveis estudadas. Os valores médios obtidos considerando todas as variáveis foram de $99,99 \%$ para o fosfato bicálcico, de $84,67 \%$ para o calcário calcítico e $75,28 \%$ para o calcário dolomítico.

Os valores da disponibilidade relativa de cálcio provavelmente não foram influenciados pelo grau de moagem ou pelo tamanho das partículas das fontes testadas, visto que a granulometria das mesmas era parecida. Segundo Griffith \& Schexnailder (1970), ocorre maior disponibilidade de cálcio nas fontes cujas partículas são maiores, por ocorrer maior retenção do alimento na parte superior do trato gastrintestinal. Esta retenção propiciaria maior período de permanência do alimento em ambiente ácido, ocasionando maior solubilização do cálcio e fósforo.

O valor da disponibilidade de cálcio de $84,67 \%$ para o calcário calcítico obtido neste experimento está dentro da faixa obtida por Reid \& Weber (1976), que, trabalhando com frangos de corte, encontraram valores de disponibilidade 73,3 a 109,4\% em algumas amostras de calcário calcítico. Não foi citado o tamanho das partículas das fontes de calcário, nem outros fatores que pudessem explicar esta variação. Valores semelhantes de disponibilidade de cálcio no calcário calcítico foram obtidos por Waldroup et al. (1964), como sendo de 84 a 100\%. Entretanto, autores como Fialho et al. (1992) encontraram valores de biodisponibilidade de cálcio no calcário calcítico de $97,75 \%$ e Ross et al. (1984), de 95 a 99\%.

O calcário dolomítico não deve ser utilizado em rações para monogástricos tendo como a principal restrição o seu elevado teor de magnésio, quando comparado a outras fontes, uma vez que o excesso deste cátion pode trazer prejuízos à absorção de cálcio. De acordo com Nugara \& Edwards Jr. (1963), o seu uso ocasionaria redução no crescimento e aumento da mortalidade em frangos de corte. Entretanto, Peixoto (1994) e Fernandes et al. (2000) não encontraram restrições ao seu uso em dietas para pintos de corte, no período de 1 a 28 dias.

O valor médio da disponibilidade relativa do cálcio no calcário dolomítico foi de 75,28\%, estando de acordo com aqueles obtidos por Ross et al. (1984), que observaram em duas fontes de calcário dolomítico baixos valores de disponibilidade de cálcio $(51,0 \mathrm{e}$ $78 \%$ ), devido ao seu alto teor de magnésio.

Veloso et al. (1995) determinaram a biodisponibilidade de cálcio em seis fontes desse mineral para frangos de corte, como a seguir: calcário calcítico, 99,0\%; fosfato bicálcico, 76,4\%; farinha de ossos calcinada, $63,0 \%$; fosfato bicálcico semidesfluorizado, 40,4\%; fosfato de Araxá, 17,2\%; e fosfato de Patos de Minas, 13,2\%. Em diversos trabalhos para determinação da disponibilidade de fósforo, o fosfato bicálcico é utilizado como padrão, sendo considerado $100 \%$ disponível (Gomes et al., 1989; Veloso et al., 1990; De Groote et al., 1991; Lima, 1995). Neste experimento, o valor da disponibilidade de cálcio no fosfato bicálcico foi de $99,99 \%$, sendo praticamente $100 \%$ disponível. Segundo Veloso 
Tabela 7 - Valores de disponibilidade relativa do cálcio no fosfato bicálcico e nos calcários calcítico e dolomítico

Table 7 - Values of relative calcium availability in the dicalcium phosphate and in the calcitic and dolomitic limestones

\begin{tabular}{|c|c|c|c|c|}
\hline \multirow[t]{2}{*}{$\begin{array}{l}\text { Variáveis } \\
\text { Variables }\end{array}$} & \multicolumn{4}{|c|}{$\begin{array}{c}\text { Disponibilidade relativa do cálcio (\%) } \\
\text { Calcium relative availability }\end{array}$} \\
\hline & $\begin{array}{c}\text { Carbonato } \\
\text { de cálcio }{ }^{1} \\
\text { Calcium } \\
\text { carbonate }\end{array}$ & $\begin{array}{c}\text { Fosfato } \\
\text { bicálcico } \\
\text { Dicalcium } \\
\text { phosphate }\end{array}$ & $\begin{array}{l}\text { Calcário } \\
\text { calcítico } \\
\text { Calcitic } \\
\text { limestone }\end{array}$ & $\begin{array}{c}\text { Calcário } \\
\text { dolomítico } \\
\text { Dolomitic } \\
\text { limestone }\end{array}$ \\
\hline $\begin{array}{l}\text { Ganho de peso } \\
\text { Weight gain }\end{array}$ & 100 & 99,99 & 82,29 & 69,62 \\
\hline $\begin{array}{l}\text { Conversão alimentar } \\
\text { Feed:gain ratio }\end{array}$ & 100 & 111,45 & 68,07 & 66,35 \\
\hline $\begin{array}{l}\text { Cálcio no osso }(\%)^{4} \\
\text { Cálcio no osso }(g)^{5}\end{array}$ & 100 & 57,20 & 70,87 & 68,73 \\
\hline $\begin{array}{l}\text { Bone calcium }(\%) \\
\text { Bone calcium }(\mathrm{g})\end{array}$ & 100 & 87,36 & 87,37 & 59,35 \\
\hline $\begin{array}{l}\text { Resistência à quebra do osso }(\mathrm{kgf})^{6} \\
\text { Bone fracture resistance }\end{array}$ & 100 & 116,99 & 107,70 & 92,91 \\
\hline $\begin{array}{l}\text { Cinza no osso }(\%)^{7} \\
\text { Bone ash }(\%)\end{array}$ & 100 & 129,69 & 94,83 & 107,01 \\
\hline $\begin{array}{l}\text { Cinza no osso }(\mathrm{g})^{8} \\
\text { Bone ash } g\end{array}$ & 100 & 97,28 & 81,58 & 62,96 \\
\hline $\begin{array}{l}\text { Média } \\
\text { Mean }\end{array}$ & 100 & 99,99 & 84,67 & 75,28 \\
\hline
\end{tabular}

${ }^{1}$ Atribui-se ao carbonato de cálcio o valor de $100 \%$ de disponibilidade de cálcio (The value of $100 \%$ calcium availability refers to the calcium carbonate).

$2 \hat{Y}=-64,3727+314,602 \times 1+13,2162 \times 2+13,2144 \times 3+10,8756 \times 4+9,20102 \times 5$

${ }^{3} \hat{Y}=3,89165-1,06567 \times 1-0,0158954 \times 2-0,017716 \times 3-0,0108199 \times 4-0,010547 \times 5$

$4 \hat{\mathrm{Y}}=5,1923+8,1657 \times 1+0,318464 \times 2+0,182166 \times 3+0,225688 \times 4+0,218875 \times 5$

$R^{2}=0,73$

$5 \hat{Y}=-0,033296+0,137328 \times 1+0,0212852 \times 2+0,0185961 \times 3+0,0185964 \times 4+0,0126324 \times 5$

$R^{2}=0,84$

${ }^{6} \hat{\mathrm{Y}}=-3,36658+5,94136 \times 1+0,624438 \times 2+0,730518 \times 3+0,672531 \times 4+0,580136 \times 5$

$R^{2}=0,88$

$7 \hat{Y}=11,0882+17,1011 \times 1+0,873579 \times 2+1,13297 \times 3+0,828448 \times 4+0,934801 \times 5$

$8 \hat{\mathrm{Y}}=-0,098896+0,335862 \times 1+0,045063 \times 2+0,043836 \times 3+0,036761 \times 4+0,028372 \times 5$

$R^{2}=0,92$

$R^{2}=0,81$

$R^{2}=0,88$

et al. (1995), os valores da disponibilidade biológica de cálcio são quase equivalentes aos de fósforo e possuem alta correlação entre si $(0,96)$, concordando com as citações de Dilworth et al. (1964), Cromwell (1989) e Furtado (1991), os quais afirmam que, em um mesmo material, os índices de biodisponibilidade de cálcio são aproximadamente similares ao de fósforo.

\section{Conclusões}

Sugere-se o valor de $1,02 \%$ de cálcio como a exigência para frangos de corte de 1 a 21 dias de idade. Contudo, levando-se em consideração a resistência à quebra óssea, que é uma variável importante no abate e processamento das aves, a exigência de cálcio para frangos de corte de 1 a 21 dias seria de 1,20\%.
Os valores médios da disponibilidade relativa de cálcio, considerando-se todas as variáveis estudadas, foi de $99,99 \%$ para o fosfato bicálcico, $84,67 \%$ para o calcário calcítico e $75,28 \%$ para o calcário dolomítico.

\section{Literatura Citada}

AZEVEDO, A. Níveis de flúor, cálcio e fósforo em rações de frango de corte. Viçosa, MG: Universidade Federal de Viçosa, 1980. 104p. Dissertação (Doutorado em Zootecnia) - Universidade Federal de Viçosa, 1980.

BRUGALLI, I. Efeito da granulometria na biodisponibilidade de fósforo e nos valores energéticos da farinha de carne e ossos e exigência nutricional de fósforo para pintos de corte. Viçosa, MG: Universidade Federal de Viçosa, 1996. 83p. Dissertação (Mestrado em Zootecnia) - Universidade Federal de Viçosa, 1996.

CABRAL, G.H. Níveis de cálcio em rações para frango de corte. Viçosa, MG: Universidade Federal de Viçosa, 1996. 
83p. Tese (Doutorado em Zootecnia) - Universidade Federal de Viçosa, 1999.

CRENSHAW, T.D.; PEO, E.R.; LEWIS, A.J. et al. Bone strength as a trait for assessing mineralization in swine: a critical review of techniques involved. Journal of Animal Science, v.53, n.3, p.828-835, 1981.

CROMWELL, G.L. Requirements, biological availability of calcium, phosphorus for swine evaluated. Feedstuffs, v.61, p.16-20, 1989.

DE GROOTE, G.; KeTElS, P.; SEYNAEVE, P. Relative bioavailability of phosphorus in meat meals as influenced by particle size. In: INTERNATIONAL POULTRY CONGRESS, 6., Instambul, 1991. Proceedings... Instambul, s.ed., 1991. p.1-11.

DILWORTH, B.C.; DAY, E.J.; HILL, J.E. Availability of calcium in feed grade phosphate to the chick. Poultry Science, v.43, p.1132-1134, 1964.

EDWARDS JR., H.M. Effect of dietary calcium, phosphorus, chloride and zeolite on the development of tibial dyschondroplasia. Poultry Science, v.67, p.1436-1446, 1988.

EDWARDS JR., H.M.; DUNAHOO, W.S.; CARMON, J.L. et al. Effect of protein, energy and fat content of the ration on calcium utilization. Poultry Science, v.39, p.1389-1394, 1960.

EDWARDS JR., H.M.; ELLIOT, M.A.; SOONCHARERNYING, S. Effect of dietary calcium in tibial dyschondroplasia. Interaction with light, cholecalcifero, 1,25-dihydroxycholecalciferol, protein and synthetic zeolity. Poultry Science, v.71, p.2041-2055, 1992.

EDWARDS JR., H.M.; MARION, J.E.; FULLER, H.L. et al. Studies on calcium requirements of broilers. Poultry Science, v.42, p.699-703, 1963.

EDWARDS JR., H.M.; VELTMANN Jr., J.R. The role of calcium and phosphorus in the etiology of tibial dyschrondroplasia in young chicks. Journal Nutrition, v.113, p.1568-1575. 1983 .

EUCLYDES, R.F.; ROSTAGNO, H.S. Estimativas dos níveis nutricionais via experimentos de desempenho. In: WORKSHOP LATINO-AMERICANO AJINOMOTO BIOLATINA, 2001, Foz do Iguaçu, p.77-88, 2001.

FERNANDES, A.L.S.; PEIXOTO, R.R. Avaliação de calcários dolomíticos como fontes de cálcio para frangos de corte em crescimento. Revista da Sociedade Brasileira de Zootecnia, v.29, n.6, p.2260-2267, 2000.

FIALHO, E.T.; BARBOSA, H.P.; BELLAVER, C. et al. et al. Avaliação nutricional de algumas fontes de suplementação de cálcio para suínos-biodisponibilidade e desempenho. Revista da Sociedade Brasileira de Zootecnia, v.21, n.5, p.891-905, 1992.

FURTADO, M.A.O. Determinação da biodisponibilidade de fósforo em suplementos de fósforo para aves e suínos. Belo Horizonte: Universidade Federal de Minas Gerais, 1991. 61p. Dissertação (Mestrado em Zootecnia) - Universidade Federal de Minas Gerais, 1991.

GOMES, P.C.; ALBINO, L.F.T.; SILVA, M.A. Criação de frangos de corte. Viçosa, MG: Universidade Federal de Viçosa, 1996. p.18.

GOMES, P.C.; ROSTAGNO, H.S.; PEREIRA, J.A.A. et al. Exigência de fósforo total e disponível e sua disponibilidade em fosfatos de rocha para suínos na fase inicial (13 a 37 $\mathrm{kg}$ ). Revista da Sociedade Brasileira de Zootecnia, v.18, n.1, p.64-76, 1989
GRIFFITH, M.; SCEXNAILDER, R. The relation of dietary particle size on the utilization of phosphates by chicks. Poultry Science, v.49, p.1271-1274, 1970.

GUEGUEN, L. La disponibilité du calcium des aliments. Cahiers Nutrition Dietetic, v.25, p.233-236, 1990.

HULAN, H.W.; De GROOTE, G.; FONTAINE, G. et al. The effect of different totals and rations of dietery calcium and phosphorus on the perfomance and incidence of leg abnormalities of male and female broiler chickens. Poultry Science, v.64, p.1157-1169, 1985.

HURWITZ, S.; PLAVNIK, I.; SHAPIRO, A. et al. Calcium metabolism and requirements of chicks are affect by growth. Journal Nutrition, v.2, p.2679-2686, 1995.

KIDD, M.T.; LERNER, S.P.; ALLARD, J.P. et al. Threonine needs of finishing broilers: growth, carcass and economic responses. Journal of Applied Poultry Research, v.8, p.160-169, 1999.

LIMA, I.L. Disponibilidade de fósforo e de flúor de alguns alimentos e exigência nutricional de fósforo para frangos de corte. Viçosa, MG: Universidade Federal de Viçosa, 1995. 121p. Tese (Doutorado em Zootecnia) - Universidade Federal de Viçosa, 1995.

MAYNARD, L.A.; LOOSLY, J.K.; HINTZ, H.F. et al. Nutrição animal. 3.ed., Rio de Janeiro:Freita Bastos, 1984. 736 p.

NATIONAL RESEARCH COUNCIL - NRC. Nutrients requirements of poultry. 8.ed. Washington, D.C.: 1984. $148 \mathrm{p}$.

NATIONAL RESEARCH COUNCIL - NRC. Nutrients requirements of poultry. 9.ed. Washington, D.C.: 1994. $155 \mathrm{p}$.

NUGARA, D.; EDWARDS JR., H. Influence of dietary calcium and phosphorus level on the magnesium requirement of the chick. Journal Nutrition, v.80, p.181-184, 1963.

NUNES, I.J. Nutrição animal básica. Belo Horizonte: 1995. $334 \mathrm{p}$.

OSORIO, J.G.; JENSEN, L.S. Biological availability of phosphorus from a Venezuelan rock phosphate for broiler chickens. Nutrition Report International, v.33, p.545$552,1986$.

PEIXOTO, R.R. Calcários sulriograndenses como fonte de cálcio para aves. XX. Avaliação do calcário dolomítico DB de Caçapava do Sul para pintos. In: REUNIÃO ANUAL DA SOCIEDADE BRASILEIRA DE ZOOTECNIA, 31., 1994, Maringá. Anais... Maringá: Sociedade Brasileira de Zootecnia, 1994. p.60.

REIDE, L.; WEBER, C.W. Calcium availability and trace minerals composition of feed grade calcium supplements. Poultry Science, v.55, p.695-712, 1972.

ROJAS, E.; RANGEL, J.L.; BEZARES, A. et al. Determinacion do fosforo disponible en una roca fosforica y su empleo en dietas para aves. Veterinary Mexico, v.11, p.1-5, 1980.

ROSS, R.D.; CROMWELL, G.L.; STAHLY, T.S. Effects of source and the particle size on the biological availability of calcium in calcium supplements for growing pigs. Journal Animal Science, v.59, p.125-134. 1984.

ROSTAGNO, H.S.; ALBINO, L.F.T.; DONZELE, J.L. et al. Tabelas brasileiras de aves e suínos; composição de alimentos e exigências nutricionais. 1.ed. Viçosa, MG: Universidade Federal de Viçosa, 2000. 141p.

ROWLAND, L.O.; DAMRON JR., B.L.; ROSS, E. et al. Comparisons of bone characteristics between floor and battery grown broilers. Poultry Science, v.50, p.1121-1124, 1971. 
RUNHO, R.C.; GOMES, P.C.; ROSTAGNO, H.S. et al. Exigência de fósforo disponível para frangos de corte machos e fêmeas. Revista Brasileira de Zootecnia, v.30, n.1, p.187-196, 2001

SHAFEY, T.M.; McDONALD, M.W. The effects of dietary concentrations of minerals, source of protein, amino acids and antibiotics on the growth and digestibility of amino acids by broiler chickens. British Poultry Science, v.32, p.535-544, 1991

SILVA, D.J. Análise de alimentos (métodos químicos e biológicos). 2.ed. Viçosa, MG: Universidade Federal de Viçosa, 1998. $165 \mathrm{p}$.

UNDERWOOD, E.J. Los minerales en la nutricion del Ganado. Zaragoza: Acribia, 1981. 210p.

UNIVERSIDADE FEDERAL DE VIÇOSA - UFV. Central de Processamento de Dados - UFV/CPD. SAEG - Sistema para análise estatística e genética, versão 7.0 Viçosa, MG: Universidade Federal de Viçosa, 1997. 54p.

VELOSO, J.A.F.; BESSA, L.H.F. Biodisponibilidade de cálcio em seis suplementos de fósforo e/ou de cálcio para frangos de corte. Arquivo Brasileiro de Medicina Veterinária, v.47, v.1, p.819-829, 1995.

VELOSO, J.A.F.; REZENDE, M.J.M.; FERREIRA, W.M. et al. Biodisponibilidade de cálcio de cinco fosfatos semielaborados para frangos de corte. In: REUNIÃO DA SOCIEDADE BRASILEIRA DE ZOOTECNIA, 27., 1990, Campinas. Anais... Campinas: Sociedade Brasileira de Zootecnia, 1990. p.113.
VELOSO, J.A.F.; REZENDE, M.J.M.; HOSSAIN, S.M. et al. Biodisponibilidade de cálcio de cinco fosfatados semi-elaborados para frangos de corte. In: REUNIÃO DA SOCIEDADE BRASILEIRA DE ZOOTECNIA, 31., 1994, Maringá. Anais... Maringá: Sociedade Brasileira de Zootecnia, 1994. WALDROUP, P.W. Bioassays remain necessary to estimate phosphorus, calcium bioavailability. Feedstuffs, v.68, p.13-20, 1996.

WALDROUP, P.W.; AMMERMAN, C.B.; HARMS, R.H. The utilization by the chicks of calcium from different sources. Poultry Science, v.43, n.1, p.212-216, 1964.

WALDROUP, P.W.; MITCHELL, R.J.; HAZEN, K.R. The phosphorus needs of finishing broilers in relationship to dietary nutrient density levels. Poultry Science, v.53, p.1655-1663, 1974.

YATES, J.D.; BRUNSON, C.C. Quality of cage reared broilers. Poultry Science, v.50, n.5, p.1648, 1971.

YOSHIDA, M.; HOSHII, H. Reevaluation of requirement of calcium and available phosphorus for starting meat-type chicks. Japanese Poultry Science, v.19, p.101-109, 1982.

Recebido em: 15/05/02

Aceito em: 22/03/03 